\title{
Rapid identification of sound direction in blind footballers
}

Authors: Takumi Mieda ${ }^{\mathrm{a},{ }^{*}}$, Masahiro Kokubu $^{\mathrm{b}}$, and Mayumi Saito ${ }^{\mathrm{b}}$

\section{Affiliations:}

${ }^{a}$ Graduate School of Comprehensive Human Sciences, University of Tsukuba, 1-1-1 Tennodai, Tsukuba, Ibaraki, 305-8574, Japan

${ }^{\mathrm{b}}$ Faculty of Health and Sport Sciences, University of Tsukuba, 1-1-1 Tennodai, Tsukuba, Ibaraki, 305-8574, Japan

\section{Corresponding author:}

Takumi Mieda

Graduate School of Comprehensive Human Sciences, University of Tsukuba, 1-1-1 Tennodai, Tsukuba, Ibaraki, 305-8574, Japan

Phone: +81-29-853-2642

E-mail: taku.mie48@gmail.com (T. Mieda) 


\section{Introduction}

In blind football, players are required to localize the position of the ball, teammates, and opponents by using auditory information during the game and daily training situations, wherein visual information cannot be utilized. In particular, identification of the sound source plays a crucial role in allowing players to determine the positions of opposing players and the ball, where the locations of the sound sources change on a moment-to-moment basis. For instance, the sound system employed is inside the ball, which makes a noise when it rolls and bounces. The sound allows players to identify the changeable location of the ball. Additionally, defense players must clearly and audibly say the word "go," or "voy," when seeking, tackling, or searching for the ball so that the possessor of the ball can identify the location of the opponents and alter his/her direction to avoid hitting them. The sighted persons on the team, who include the coach, goalkeeper, and guide (who stays behind the opponent goal), are allowed to give their players spatial information, such as directions and distances against relevant opponents. Accordingly, rapid and accurate sound identification with auditory information is quite important based on the characteristics of playing blind football.

In general, sound localization refers to judgements of the direction and distance of a sound source (e.g., Moore, 2013). Some studies report auditory spatial deficits in blind children in their absolute judgement of sound direction (Cappagli and Gori, 2016) and in blind adults in their relative judgement of sound direction (Gori et al. 2013) when compared to sighted individuals. On the other hand, studies have shown that blind individuals perform as well as sighted individuals in their absolute judgement of sound direction (Gori et al. 2013) and even have supra-normal abilities when compared with sighted individuals in their relative judgement of sound direction (Fieger et al. 2006; Röder et al. 1999; Voss et al. 2004), which is assumed to be attributed to compensation for visual loss. Velten et al. $(2014,2016)$ have demonstrated that blind footballers are more precise than blind and sighted individuals in identifying sound direction by using finger snap sounds emitted from loudspeakers. These results suggest that precise identifications of sound directions in blind footballers are enhanced by regular training in blind football. Velten and colleagues (2016) state that auditory spatial information must be quickly and accurately perceived and interpreted in order to afford proper decision making in blind football. Thus, it is important to ascertain whether blind footballers can quickly and accurately identify sound directions. In the previous 
study, however, the speed of identifications of sound directions by blind footballers was not investigated. We assume that the speed of sound identifications can also be enhanced by long-term training of blind football. Even though there is a trade-off relationship between reaction time (RT) and accuracy (Pew, 1969), previous studies have shown that sports experts can make faster choice responses than non-experts without sacrificing accuracy (Kida et al. 2005; Mori et al. 2002). These findings motivated our study to investigate whether blind footballers can identify sound directions rapidly while maintaining accuracy.

Humans benefit from inter-aural differences in time and intensity, as well as the spectral content of the stimulus, when localizing a sound (e.g., Doucet et al. 2005). Several studies have referred to the occurrence of front-back confusion (Makous and Middlebrooks, 1990; Middlebrooks and Green, 1991; Perrett and Noble, 1997; Wightman and Kistler, 1999), in which a stimulus in front of a subject is localized to the rear, or vice versa (Middlebrooks and Green, 1991), due to cone of confusion (Grothe et al. 2010; Letowski and Letowski, 2012). Velten et al. (2016) reported that blind footballers showed less front-back confusion than blind and sighted individuals. While playing blind football, it is necessary for blind footballers to identify sound directions rapidly by using auditory cues for front-back and left-right localization. Therefore, it is assumed that blind footballers would be faster than sighted individuals in identifying sound direction with less front-back confusion.

Here, we conducted three types of auditory RT tasks and measured RTs. First, we utilized simple RT tasks to investigate the processing of auditory input and motor output. Second, we employed a two-choice RT task requiring front-back localization. Last, we also employed a four-choice RT task requiring both left-right and front-back localization. Rapid identification of the sound source was assessed by two- and four-choice RT tasks. For the two-choice RT task, participants only identified the sound source as being in front or behind them, wherein responses with the left and right foot were performed in separate blocks. For the four-choice RT task, participants used their left or right foot for the stepping response toward the sound source (i.e., right foot towards the rightward auditory stimulus and left foot towards the leftward auditory stimulus). The comparison of choice RTs between two- and four-choice RT tasks assisted in distinguishing whether the processing of identifying sound direction or the choice of the left or right foot for the response influenced choice RTs.

Perceptual and cognitive skills have previously been evaluated by comparing RTs to visual and 
auditory stimuli between simple and choice RT tasks. For instance, Kida et al. (2005) reported that baseball experts had shorter RTs than tennis players and nonathletes in a Go/Nogo RT task but not in a simple RT task. Blind individuals also showed superior auditory choice RTs compared with sighted individuals in a divided attention task (Kujala et al. 1997) and a spatial attention task (Chen et al. 2006). Moreover, early-blind individuals had shorter RTs than sighted individuals in selective attention tasks, but not in a simple RT task, indicating enhanced attentional performance in early-blind individuals (Collignon and De Volder, 2009; Collignon et al. 2006). Based on previous studies, it was assumed that blind footballers with visual impairments would have shorter auditory choice RTs than sighted nonathletes. Given the superiority of blind footballers in choice RT tasks, it should be determined whether their shorter choice RTs are due to rapid identification of sound direction or faster processing of auditory input and motor output. However, it remains unknown whether blind footballers have shorter auditory simple RTs and choice RTs than sighted athletes, who are required to produce a faster response largely in the visual modality.

Taken together, the present study aimed to compare simple RT, choice RT, and response accuracy among blind footballers, sighted footballers, and nonathletes. We hypothesized that blind footballers would have shorter RTs than sighted footballers in the choice RT tasks, but not in the simple RT task. We also hypothesized that blind footballers would show higher overall response accuracy and less front-back confusion.

\section{Methods}

\section{Participants}

Participants were blind footballers $(n=10$; mean age $=27.6 \pm 5.3$ years; playing experience $=$ $8.0 \pm 4.2$ years $)$, sighted college footballers $(\mathrm{n}=11$; mean age $=19.2 \pm 1.2$ years; playing experience $=$ $12.4 \pm 2.2$ years $)$, and healthy sighted nonathletes $(n=11$; mean age $=22.7 \pm 2.9$ years; no regular exercise or training), based on the experimental design of the previous study (Campayo-Pierna et al. 2017). The sample size was based on an a priori power analysis for the within-between interaction in a repeated measures ANOVA (estimated effect size of $f=.25, \alpha=.05$, power $=.80$, number of groups $=3$, number of measurements $=3$, estimated correlation among repeated measures $=.60$, non-sphericity 
correlation = 1) performed using G*Power 3 (Faul, Erdfelder, Lang, and Buchner, 2007), which indicated the need for a minimum of 30 participants in total. All participants were male and their foot preferences (i.e., the leg preferred to kick a ball) were self-declared. Of the 32 participants, 31 were right-footed; the remaining participant was a left-footed nonathlete. The group of "blind footballers" in the present study included totally blind and low-vision individuals who play and regularly train in blind football. Five players were in B1, and the other five were in B2, according to the classification rules of the International Blind Sports Federation (http://www.ibsasport.org/classification/), which defines B1 players as those who have a visual acuity lower than LogMAR 2.60 and B2 players as those who have visual acuity ranging from LogMAR 1.5-2.6 and/or visual field constricted to a diameter of less than 10 degrees. The characteristics of the blind footballers are shown in Table 1. One B1 player lost his vision before the age of 2 years; one lost his vision between the ages of 9-10 years; and three lost their vision between the ages of 18-30 years. Four B2 players had congenital visual impairment and one had visual impairment at the age of 4 years. The present study was conducted in accordance with the Declaration of Helsinki and approved by the local Ethics Committee. Informed consent was provided by all participants prior to the experiments, and they had no history of hearing deficiencies or neurological impairments.

Insert Table 1 about here

\section{Apparatus and auditory stimuli}

Fig. 1 shows a top-down view of the experimental setup. The experiment room $(7.3 \mathrm{~m} \times 7.3 \mathrm{~m}$ $\times 2.5 \mathrm{~m}$ ) was not anechoic. Four loudspeakers (SP-2416; Hashy-Topin Co., Ltd., Tokyo, Japan) were positioned in the front-left, front-right, back-left, and back-right locations at a radius of $1.68 \mathrm{~m}$ from the center of a sensor mat $40 \mathrm{~cm} \times 40 \mathrm{~cm} \times 1.3 \mathrm{~cm}$ in size (Takei Scientific Instruments Co., Ltd., Tokyo, Japan). Thin threads were attached to the top surface of the sensor mat in order to provide the participants standing on the mat with spatial information about the original position. The sensor mat was divided into two areas at the center line, which allowed for the separate detection of each foot. The sensor mat recorded participant RTs from the point of release of the foot. The threshold for foot release on the sensor 
mat was $39.2 \mathrm{~N} / 80 \mathrm{~cm}^{2}$. The RT measurement error was $\pm 2 \mathrm{~ms}$.

Auditory stimuli $(1,000 \mathrm{~Hz}$, pure tone) were utilized to evaluate accuracy for the front-back and left-right localization tasks (Aggius-Vella et al. 2017). The stimuli were generated by a customized program on a laptop computer (Intel Core i7-5600U CPU, $2.60 \mathrm{GHz}$ ). There were audible click noises due to spectral splatter. The sound pressure level $(53.3 \pm 4.22 \mathrm{~dB})$ within the speakers was recorded using a sound collector (CENTER 322; MK Scientific, Inc., Yokohama, Japan) by generating stimuli from each loudspeaker in the same environment as the actual experiment. The amplitude of the stimuli was measured at the position of each participant's head. The rise time was approximately $3 \mathrm{msec}$. Each loudspeaker generated a beep sound until the release of either foot from the mat toward the location of the activated loudspeaker. The loudspeakers were positioned at ear height for each participant. The absolute angle between the axis of each loudspeaker and the frontal plane of the participant was $45^{\circ}$. The movements of the two infrared markers attached to each participant's foot were recorded by six high-speed cameras (OptiTrack Flex13, 120 fps; NaturalPoint Inc. Corvallis, OR, USA) and analyzed to ensure that the participants correctly detected the location of the activated loudspeaker.

Insert Fig. 1 about here

Task

The participants were instructed to execute a goal-directed stepping response towards the perceived direction of the sound source (i.e., a loudspeaker) as quickly and as accurately as possible. The pointing method that uses a body part or an extension of a body part has been found to be more accurate than other methods involving a verbal description for indicating the perceived direction of auditory targets in a horizontal plane in blind and sighted individuals (Haber et al. 1993). Particularly, it has been shown that pointing with feet was as accurate as pointing with hands in sighted individuals when localizing sound directions in a horizontal plane (Aggius-Vella et al. 2017). Moreover, some studies demonstrated an advantage of experts' skill compared with nonexperts, under a condition in which perception and action were naturally coupled (Farrow and Abernethy, 2003; Mann et al. 2010). According to the 
literature, it appears to be necessary to investigate the skills of experts in tasks relevant to their actual action. Taking these findings together, it is suggested that the stepping response with feet can be beneficial for assessing auditory RTs and accuracy of both blind footballers and sighted individuals when localizing horizontal sound direction under nonvisual information conditions.

The participants were instructed to face forward without turning their head or trunk and to refrain from leaning their upper body forward. The sound ceased upon release of the foot from the sensor mat. The participants were instructed to respond to auditory stimuli from the front-right and back-right directions with their right foot, and to auditory stimuli from the front-left and back-left directions with their left foot. They were instructed to return the foot to the sensor mat after executing a stepping response. Afterward, they took their both feet off the mat to reset the load thereon, and then returned to the original position to confirm that they were ready for the next trial. The interval between the return of the participant to the original position and the presentation of the next set of auditory stimuli was randomly set to 3, 4, or $5 \mathrm{~s}$. Each participant executed three different tasks during the experiment. In the simple RT task, participants were informed in advance regarding which loudspeaker was activated, which meant that they only responded to the informed sound direction. The two-choice RT task was conducted separately on the left and right sides. Auditory stimuli were randomly presented from one of the two loudspeakers located at the front and back sides in the two-choice RT task, and from one of four loudspeakers in the four-choice RT task. The frequency of sound of the loudspeakers was equal in all choice RT tasks.

\section{Procedure}

The participants were blindfolded with an eye mask throughout the experiment. They were instructed to stand at the center of the sensor mat wearing socks. Two markers were attached to the top of their feet. The order of simple and choice RT tasks was not counter-balanced in previous studies (e.g., Collignon and De Volder 2009; Collignon et al. 2006). We assumed that it was difficult for non-blind footballers to perform the choice RT tasks before the simple RT task because they were not familiar with the choice RT tasks for identifying sound directions based only on auditory information. Thus, the simple RT task was performed, followed by the two- and four-choice RT tasks for all participants. In the simple 
RT task, two practice trials for each loudspeaker were conducted in the clockwise order. During the actual test, 20 trials were completed per participant ( 5 trials $\times 4$ loudspeakers). In the two-choice RT task, half of the participants started on the left side and the other half on the right side, during both the practice and actual trials. Two practice trials for each loudspeaker were separately conducted on the left and right sides. During the actual test, a total of 48 trials were completed per participant (12 trials $\times 4$ blocks). In the four-choice RT task, one practice trial for each loudspeaker was completed randomly. During the actual test, a total of 48 trials were completed per participant (12 trials $\times 4$ blocks). The order of activated loudspeakers was randomized in the two- and four-choice RT tasks. Participants had a 2-minute break between the blocks and a 5-minute break between the tasks. All participants completed a total of 116 trials during the experiment.

\section{Analysis}

Correct and incorrect responses were classified to calculate both auditory RT and the accuracy of sound localization. Correct responses indicated that the initial direction of movement of the infrared marker toward the auditory stimulus was the same as that toward the landing point. Auditory RT was determined as the time between the generation of a beep sound and the release of the foot from the sensor mat. Moreover, we evaluated trials as "missing" when latencies exceeded 1,000 ms and responses faster than 100 ms were considered to be anticipated (Elsner and Hommel, 2001; Van der Stoep et al. 2016; Eder and Dignath, 2017). Auditory RTs for incorrect responses were excluded from further analysis. The accuracy of sound localization was determined by the rate of correct responses. Directional error between the left and right sides was determined according to whether the landing point of a marker was on the left or right side (i.e., left-right confusion) based on the horizontal axis at the original position. Directional error between the front and back sides (i.e., front-back confusion) was determined according to whether the landing point of a marker was in front or behind, based on the vertical axis at the original position. The Kolmogorov-Smirnov test was used to check the normal distribution of the variables and auditory RT was normally distributed $(P>0.05)$. A two-way mixed analysis of variance (ANOVA) was performed to analyze auditory RTs with the within-participant factor of task (simple, two-choice, and four-choice), and the between-participant factor of group (blind footballers, sighted footballers, and nonathletes). We 
conducted a main effect analysis when a significant interaction between task and group was observed. When the assumption of normality was violated, nonparametric tests such as the Kruskal-Wallis test and the Mann-Whitney U test were used. The Kruskal-Wallis nonparametric test with a Bonferroni correction was performed to analyze response accuracy, with the between-participant factor of group. We divided the blind footballers into two groups, namely the "longer experienced group" and the "shorter experienced group." A Student's t-test revealed that the longer experienced group (10.2 \pm 2.9 years) had significantly longer $(p=.005)$ experience playing blind football than the shorter experienced groups $(4.6 \pm 1.5$ years $)$. Moreover, a Student's t-test was used to compare auditory RTs in each task between the B1 and B2 players and between the longer and shorter experienced group. A Mann-Whitney $U$ test was used to compare response accuracy between the B1 and B2 players and between the longer and shorter experienced group. We also calculated choice RT - simple RT in order to investigate the extent of the time delay of choice RTs relative to simple RTs - that is, the speed of identification of sound direction. A Student's t-test was used to analyze the extent of the time delay in two-choice RTs relative to simple RTs and in four-choice RTs relative to simple RTs between the blind and sighted footballers, as well as between the B1 and B2 players. We also calculated choice RTs - simple RTs in order to analyze the influence of the playing experience of blind football on the speed of identification of sound direction between the longer and shorter experienced group. A Mann-Whitney U test was used to compare response accuracy between the playing experience of blind football between the groups. The analysis was conducted using IBM SPSS Statistics software (ver. 24.0; IBM Corp., Armonk, NY, USA). The alpha level was set at 0.05 .

\section{Results}

\section{Reaction times}

Fig. 2 shows the mean auditory RTs $( \pm \mathrm{SD})$ for the three groups on the simple, two-choice, and four-choice RT tasks. A two-way mixed ANOVA showed significant main effects of task $(F(2,58)=$ 95.44, $\left.p<.001, \eta_{p}{ }^{2}=.767\right)$ and group $\left(F(2,29)=21.50, p<.001, \eta_{p}{ }^{2}=.597\right)$, and an interaction between task and group $\left(F(4,58)=3.99, p=.006, \eta_{p}{ }^{2}=.216\right)$ with regard to auditory RT. Subsequent one-way ANOVAs revealed significant main effects of group in the simple $\left(F(2,29)=4.90, p=.015, \eta_{p}{ }^{2}=.253\right)$, 
two-choice $\left(F(2,29)=17.65, p<.001, \eta_{p}{ }^{2}=.549\right)$, and four-choice $\left(F(2,29)=22.28, p<.001, \eta_{p}{ }^{2}\right.$ $=.606)$ RT tasks. The Bonferroni-corrected post-hoc test showed significant differences between the blind and sighted footballers (two-choice, $p=.005$; four-choice, $p<.001$ ), and between the blind footballers and the nonathletes (two-choice, $p<.001$; four-choice, $p<.001$ ) on the choice RT tasks. These results indicate that the blind footballers had shorter auditory RTs (two-choice, $302 \pm 27 \mathrm{~ms}$; four-choice, $320 \pm$ $36 \mathrm{~ms}$ ) than the sighted footballers (two-choice, $367 \pm 53 \mathrm{~ms}$; four-choice, $388 \pm 33 \mathrm{~ms}$ ) and the nonathletes (two-choice, $413 \pm 43 \mathrm{~ms}$; four-choice, $417 \pm 34 \mathrm{~ms}$ ). Furthermore, a significant difference was observed between the blind footballers and the nonathletes on the simple RT task $(p=.012)$. The blind footballers had shorter auditory RTs $(261 \pm 35 \mathrm{~ms})$ than the nonathletes $(309 \pm 37 \mathrm{~ms})$. However, no significant differences were observed between the blind and sighted footballers $(287 \pm 35 \mathrm{~ms})$ on the simple RT task $(p=.304)$. Moreover, no significant differences were observed between the sighted footballers and the nonathletes on all RT tasks (simple, $p=.455$; two-choice, $p=.054$; four-choice, $p$ $=.174$ ). A Student's t-test showed no significant difference of RTs between the B1 and B2 players (simple, $p=.211$; two-choice, $p=.099$; four-choice, $p=.265)$ or between the longer and shorter experienced group (simple, $p=.534$; two-choice, $p=.402$; four-choice, $p=.494$ ).

Fig. 3 shows that the mean difference between two-choice RTs and simple RTs for the blind footballers $(41 \pm 26 \mathrm{~ms})$ was smaller $(p=.016)$ than that of the sighted footballers $(81 \pm 40 \mathrm{~ms})$. The figure also shows that the mean difference between four-choice RTs and simple RTs for the blind footballers $(59 \pm 22 \mathrm{~ms})$ was smaller $(p=.002)$ than that of the sighted footballers $(102 \pm 31 \mathrm{~ms})$. Fig. 4 shows that the mean difference between four-choice RTs and simple RTs for the longer experienced group $(43 \pm 15 \mathrm{~ms})$ was smaller $(p=.012)$ than that of the shorter experienced group $(75 \pm 16 \mathrm{~ms})$. The mean difference between two-choice RTs and simple RTs for the longer experienced group ( $26 \pm 27 \mathrm{~ms})$ tended to be smaller than that of the shorter experienced group $(57 \pm 13 \mathrm{~ms})$, but not significantly different $(p$ $=.056)$. There were no significant differences between four-choice RTs and simple RTs $(p=.886)$ or between two-choice RTs and simple RTs $(p=.971)$ for the B1 players when compared to the B2 players.

Insert Figs. 2, 3 and 4 about here 


\section{Correct response rates}

Fig. 5 shows the median (interquartile range) of the correct response rates for the three groups on the two- and four-choice RT tasks. The Kruskal-Wallis test revealed significant differences among the groups on the two-choice $(H=12.401, p=.002)$ and four-choice $(H=9.970, p=.007)$ RT tasks. Pairwise comparisons (Bonferroni correction) of the groups showed significant differences between the blind footballers and the nonathletes on the two-choice $(p=.001)$ and four-choice $(p=.006)$ RT tasks, where the blind footballers (two-choice, 97.9\% (96.4 - 99.5\%); four-choice, 97.9\% (95.8 - 100\%)) had significantly higher correct response rates than the nonathletes (two-choice, 87.5\% (80.2 - 91.7\%); four-choice, $91.7 \%(85.3-94.8 \%))$. No significant differences were observed between the sighted footballers (two-choice, 93.8\% (87.5 - 94.8\%); four-choice, 91.7\% (90.5 - 96.9\%)) and the blind footballers (two-choice, $p=.086$; four-choice, $p=.098$ ), or between the sighted footballers and the nonathletes (two-choice, $p=.541$; four-choice, $p=.970$ ). A Mann-Whitney U test showed no significant difference of correct response rates between the B1 and B2 players (two-choice, $p=.690$; four-choice, $p$ $=.841$ ) or between the longer and shorter experienced group (two-choice, $p=.548$; four-choice, $p=.222$ ) in the choice RT tasks, respectively. Almost all error responses occurred between the front and back sides in both tasks. Left-right confusion was only observed twice in nonathletes on the four-choice RT task. Front-back confusion in the two-choice RT task occurred 12 times $(1.2 \pm 1.2$; mean $\pm \mathrm{SD})$ in the blind footballers, 41 times $(3.7 \pm 2.3)$ in the sighted footballers, and 75 times $(6.8 \pm 4.5)$ in the nonathletes. Front-back confusion in the four-choice RT task occurred 11 times $(1.1 \pm 1.1)$ in the blind footballers, 41 times $(3.7 \pm 3.4)$ in the sighted footballers, and 53 times $(4.8 \pm 3.1)$ in the nonathletes.

Insert Fig. 5 about here

\section{Discussion}

The purpose of the present study was to compare simple RT, choice RT, and response accuracy 
among blind footballers, sighted footballers, and nonathletes. The most important result was the significant interaction observed between the type of task and group. In particular, the choice RTs of the blind footballers were significantly shorter than those of the sighted footballers. On the other hand, the simple RTs of the blind footballers were not significantly different from those of the sighted footballers. Moreover, the extent of the time delay in choice RTs relative to simple RTs for the blind footballers were significantly smaller than that of the sighted footballers. These results suggest that the blind footballers were superior to the sighted footballers in identifying sound direction based on auditory cues rather than auditory input and motor output. The reason the blind footballers had shorter choice RTs than the sighted footballers seems to be related to the regular blind football training, which requires the rapid and accurate identification of sound sources under the condition where players do not know which direction the sound is coming from. Our study revealed no significant differences between the sighted footballers and the nonathletes in the comparison of RTs in the two-choice and four-choice RT tasks. We assume that sighted footballers mainly use visual but not auditory modality during daily football training in order to process spatial information, such as the positions of the ball, teammates, and opponents. This may be the reason the sighted footballers were not superior to the nonathletes in the choice RT tasks, where the blind footballers were superior to both groups. Our results support previous studies indicating that expert players possess enhanced perceptual-cognitive skills compared with non-experts (e.g., Helsen and Starkes, 1999; Mann et al. 2007; Ward and Williams, 2003); these studies mostly involved visual stimuli. Our results are in line with these findings and suggest the notion that rapid identification of sound direction is an indispensable perceptual-cognitive skill in blind footballers.

The main difference between the two- and four-choice RT tasks is that participants only have to identify whether the sound source is in front of or behind them in the two-choice RT task, whereas they must use either their left or right foot for the stepping response toward the sound source and identify sound direction in the four-choice RT task. If a difference in RT between the blind and sighted footballers had been observed only on the four-choice RT task, faster choice RTs of the blind footballers may have been attributable to faster foot choice decision-making rather than more rapid identification of the sound direction. In the present results, however, the blind footballers had shorter RTs than the sighted footballers on both two- and four-choice RT tasks. These results indicate that blind footballers can identify sounds 
rapidly located in front and behind them, rather than quickly decide regarding which foot to use, compared with sighted footballers.

The present study also found that the simple RT of the blind footballers was significantly shorter than that of the nonathletes. Some studies have shown that simple RTs for experts are not different from those for non-experts (e.g., Kida et al. 2005; Mori et al. 2002), while other studies have reported faster simple auditory RTs in athletes than in nonathletes. For instance, some studies showed shorter simple auditory RTs of sighted athletes than sighted nonathletes, in athletics (Gavkare et al. 2013), basketball (Kaur et al. 2006), table tennis (Akhani et al. 2015; Deepa and Sirdesai, 2016), and football (Akhani et al. 2015). Similarly, Yildirim et al. (2013) reported shorter simple RTs for blind goalball players than blind nonathletes, suggesting that shorter auditory simple RT is due to the experience in playing blind sports. The present results are in line with these findings, which show faster simple RTs of experts when compared to non-experts. We can assume that faster simple RTs of blind footballers are attributed not only to processing of motor output but also of auditory input, which has been improved by long-term training in blind football. Taken together, our results suggest that improved auditory simple RT is due to long-term experience of playing blind football.

With respect to the age of the participants, the blind footballers were the oldest of all groups. Auditory RTs are known to increase as age increases in adults. For instance, auditory RTs in simple and discrimination (i.e., go-no-go) RT tasks begin to slow down after the age of 20 years (Fozard et al. 1994). In our study, however, auditory RTs of the blind footballers were not significantly different from those of sighted footballers and even shorter than those of the sighted nonathletes. Thus, the difference in simple auditory RT between the blind footballers and the sighted nonathletes was not due to aging, but due to long-term training in blind football.

We compared correct response rates and front-back confusion among the three groups. Our study revealed that there was a significant main effect of group on the correct response rates, where the blind footballers could make faster choice reactions, while maintaining accuracy and the lowest amount of front-back confusion among all groups. The lowest number of front-back confusions observed in the blind footballers could be related to the ability to use auditory information in a non-visual space, an ability enhanced by daily training in blind football. One may argue that the better performance of blind 
footballers was related to the cross-modal plasticity for the processing of sounds in the blind rather than the effect of long-term experience of playing blind football. Indeed, many studies have shown that blind individuals have supra-normal abilities compared to sighted individuals in sound localization (Fieger et al. 2006; Röder et al. 1999; Voss et al. 2004), pitch discrimination (Arnaud et al. 2018; Gougoux et al. 2004; Wan et al. 2010), and sound motion (Lewald, 2013), which is assumed to be attributed to compensating for visual loss. However, Velten et al. $(2014,2016)$ indicate that blind footballers show more precise identification of sound direction and less-frequent front-back confusion than blind individuals, which is not solely due to the absence of vision and enhancement in auditory perception accuracy, but is related to the practice of blind football. Their findings seem to support our notion that long-term training in blind football can contribute to an enhancement of accuracy in sound localization.

The present study showed no significant difference in RTs and correct response rates between the B1 and B2 players in all RT tasks. There is evidence from previous work that effects of genuine blindness and low vision on auditory functions can be diametrically opposite. For instance, visually impaired individuals with residual peripheral vision localize sounds less precisely than sighted or completely blind subjects (e.g., Lessard et al, 1998). In the present study, however, correct response rates of the B2 players were not significantly different from that of the B1 players. This is because both B1 and B2 players had acquired the ability of accurate sound localization through long-term training in blind football. For this reason, it seems that the heterogeneity of the group with blindness and residual vision did not affect superior performance of accurate identification of sound direction in blind footballers. Regarding years of blind football playing experience, we observed that the extent of the time delay in four-choice RTs relative to simple RTs for the longer group was significantly smaller than that of the shorter experienced group. This result seems to be related to the idea that a long period of blind football playing experience could enhance the speed of identification of sound direction. Taken together, our results indicate that rapid sound identification of sound direction in blind footballers can be attributed to their participation in blind football rather than their visual classes.

In the present study, the B1 group was heterogeneous with respect to the onset of blindness (early vs. late). Several studies that compared auditory performance in early- and late-blind individuals have shown that early-blind individuals outperform late-onset individuals in nonvisual tasks such as a 
sound-source discrimination (Voss et al. 2004; 2008), pitch discrimination (Gougoux et al. 2004), and echolocation discrimination (Teng et al. 2012). On the basis of their results, the supra-normal abilities of blind individuals seem to be pronounced for those with an early onset than with a late onset of blindness, largely indicating the cross-modal plasticity due to the onset of blindness at an early development stage. In our study, however, no significant Pearson's correlation was observed between the age of onset of visual loss and auditory RTs (simple, $p=.500$; two-choice, $p=.144$; four-choice, $p=.152$ ) or correct response rates (two-choice, $p=.812$; four-choice, $p=.868$ ). Despite a small group of participants, these results may indicate that the performance of the B1 group was independent of the onset of blindness.

There may be a limitation that the conditions were not counterbalanced in the present study. One may argue that the better trained blind athletes could be more resistant to fatigue in a physically active task and that the effects between the groups increased as the experiment progressed. In the present study, however, the stepping response we utilized was not a physically active task. For this reason, we assume that significant differences of choice RTs among the groups were not influenced by fatigue.

Another limitation of the present study is that the experiment was conducted in a reverberant listening condition. In that condition, blind individuals compared to sighted individuals can use multiple cues such as reverberant cues (Kolarik et al. 2013) and echo cues (Dufour et al. 2005) for accurate sound localization. It is possible that these cues might influence the identification of sound directions in blind footballers. Further studies should take this into account and confirm rapid and accurate identification of sound direction in blind footballers in an anechoic listening condition.

\section{Conclusions}

The present study found that blind footballers had shorter two- and four-choice RTs, but not simple RTs, as compared to sighted footballers. These results suggest that blind footballers identify sound direction more rapidly based on auditory cues, rather than on auditory input and motor output; this essential perceptual-cognitive skill appears to be specific to blind footballers. Moreover, blind footballers showed shorter simple auditory RTs than nonathletes, which was related to their long-term experience of playing blind football. Blind footballers also showed higher overall correct response rates and a lower frequency of front-back confusion than nonathletes. These results suggest that blind footballers identify 
sound direction more rapidly, while maintaining accuracy, compared to sighted individuals. Long-term experience of playing blind football would enable visually impaired players to localize sounds more rapidly in nonvisual environments. 
Funding sources: This study was supported, in part, by a grant from the Advanced Research Initiative for Human High Performance (ARIHHP), University of Tsukuba. This study was also supported by the JSPS Grant-in-Aid for Scientific Research (C) [Grant Number 17KT0133].

Declarations of interest: none. 


\section{References}

Aggius-Vella E, Campus C, Finocchietti S, Gori M (2017) Audio spatial representation around the body. Front Psychol 8:1-11. http://dx.doi.org/10.3389/fpsyg.2017.01932

Akhani PN, Gosai H, Mendpara S, Harsoda JM (2015) Mental chronometry in table tennis players and football players: Who have faster reaction time? Int J Basic Appl Physiol 4:53-57.

Arnaud L, Gracco V, Ménard L (2018) Enhanced perception of pitch changes in speech and music in early blind adults. Neuropsychologia 117:261-270. http://doi.org/10.1016/j.neuropsychologia.2018.06.009

Campayo-Piernas M, Caballero C, Barbado D, Reina, R (2017) Role of vision in sighted and blind soccer players in adapting to an unstable balance task. Exp Brain Res 235:1269-1279. http://dx.doi.org/ 10.1007/s00221-017-4885-8

Cappagli G, Gori M (2016) Auditory spatial localization: developmental delay in children with visual impairments. Res Dev Disabil 53:391-398. http://doi.org/10.1016/j.ridd.2016.02.019

Chen Q, Zhang M, Zhou X (2006) Spatial and nonspatial peripheral auditory processing in congenitally blind people. Neuroreport 17:1449-1452. http://dx.doi.org/10.1097/01.wnr.0000233103.51149.52

Collignon O, De Volder AG (2009) Further evidence that congenitally blind participants react faster to auditory and tactile spatial targets. Can J Exp Psychol 63:287-293. http://dx.doi.org/10.1037/a0015415

Collignon O, Renier L, Bruyer R, Tranduy D, Veraart C (2006) Improved selective and divided spatial attention in early blind subjects. Brain Res 1075:175-182. http://dx.doi.org/10.1016/j.brainres.2005.12.079

Deepa HS, Sirdesai N (2016) A comparative study of auditory \& visual reaction time in table tennis players and age matched healthy controls. Indian J Clin Anat Physiol 3:408-411.

Doucet ME, Guillemot JP, Lassonde M, Gagné JP, Leclerc C, Lepore F (2005) Blind subjects process auditory spectral cues more efficiently than sighted individuals. Exp Brain Res 160:194-202. http://dx.doi.org/10.1007/s00221-004-2000-4 
Dufour A, Després O, Candas V (2005) Enhanced sensitivity to echo cues in blind subjects. Exp Brain Res 165:515-519. http://dx.doi.org/10.1007/s00221-005-2329-3

Eder AB, Dignath D (2017) Influence of verbal instructions on effect-based action control. Psychol Res 81:355-365. http://dx.doi.org/10.1007/s00426-016-0745-6

Elsner B, Hommel B (2001) Effect anticipation and action control. J Exp Psychol Human 27:229-240. http://dx.doi.org/10.1037/0096-1523.27.1.229

Faul F, Erdfelder E, Lang AG, Buchner A (2007) G* Power 3: A flexible statistical power analysis program for the social, behavioral, and biomedical sciences. Behav Res Methods 39:175-191. http://dx.doi.org/10.3758/BF03193146

Farrow D, Abernethy B (2003) Do expertise and the degree of perception-action coupling affect natural anticipatory performance? Perception 32:1127-1139. http://dx.doi.org/10.1068/p3323

Fieger A, Röder B, Teder-Sälejärvi W, Hillyard SA, Neville HJ (2006) Auditory spatial tuning in late-onset blindness in humans. J Cognitive Neurosci 18:149-157. http://dx.doi.org/10.1162/089892906775783697

Pew RW (1969) The speed-accuracy operating characteristic. Acta Psychol 30:16-26. https://doi.org/10.1016/0001-6918(69)90035-3

Fozard JL, Vercruyssen M, Reynolds SL, Hancock PA, Quilter RE (1994) Age differences and changes in reaction time: the Baltimore Longitudinal Study of Aging. J Gerontol 49:179-189. http://doi.org/10.1093/geronj/49.4.P179

Gavkare AM, Nanaware NL, Surdi AD (2013) Auditory reaction time, visual reaction time and whole body reaction time in athletes. Ind Med Gaz 6:214-219.

Gori M, Sandini G, Martinoli C, Burr DC (2013) Impairment of auditory spatial localization in congenitally blind human subjects. Brain 137:288-293. http://doi.org/10.1093/brain/awt311

Gougoux F, Lepore F, Lassonde M, Voss P, Zatorre RJ, Belin P (2004) Pitch discrimination in the early blind: People blinded in infancy have sharper listening skills than those who lost their sight later. Nature 430:309. http://doi.org/10.1038/430309a

Grothe B, Pecka M, McAlpine D (2010) Mechanisms of sound localization in mammals. Physiol Rev 90:983-1012. http://dx.doi.org/10.1152/physrev.00026.2009 
Haber L, Haber RN, Penningroth S, Novak K, Radgowski H (1993) Comparison of nine methods of indicating the direction to objects: Data from blind adults. Perception 22:35-47. http://doi.org/10.1068/p220035

Helsen WF, Starkes JL (1999) A multidimensional approach to skilled perception and performance in sport. Appl Cognitive Psych 13:1-27. http://dx.doi.org/10.1002/(SICI)1099-0720(199902)13:1<1::AID-ACP540>3.0.CO;2-T

International Blind Sports Federation Definition of Visual Classes. http://www.ibsasport.org/classification/. Accessed 29 June 2019

Kaur P, Paul M, Sandhu JS (2006) Auditory and visual reaction time in athletes, healthy controls, and patients of type 1 diabetes mellitus: A comparative study. Int J Diabetes Dev Ctries 26:112-115.

Kida N, Oda S, Matsumura M (2005) Intensive baseball practice improves the Go/Nogo reaction time, but not the simple reaction time. Cognitive Brain Res 22:257-264. https://doi.org/10.1016/j.cogbrainres.2004.09.003

Kolarik AJ, Cirstea S, Pardhan S (2013) Evidence for enhanced discrimination of virtual auditory distance among blind listeners using level and direct-to-reverberant cues. Exp Brain Res 224:623-633. https://doi-org.ezproxy.tulips.tsukuba.ac.jp/10.1007/s00221-012-3340-0

Kujala T, Lehtokoski A, Alho K, Kekoni J, Näätänen R (1997) Faster reaction times in the blind than sighted during bimodal divided attention. Acta Psychol 96:75-82. http://dx.doi.org/10.1016/S0001-6918(97)00007-3

Lessard N, Paré M, Lepore F, Lassonde M (1998) Early-blind human subjects localize sound sources better than sighted subjects. Nature 395:278-280. http://dx.doi.org/10.1038/26228

Letowski TR, Letowski ST (2012) Auditory spatial perception: Auditory localization. Army Research Laboratory Aberdeen Proving Ground MD Human Research and Engineering Directorate. http://www.dtic.mil/cgi-bin/GetTRDoc?AD=ADA562292/. Accessed 23 December 2018

Lewald J (2013) Exceptional ability of blind humans to hear sound motion: implications for the emergence of auditory space. Neuropsychologia 51:181-186. http://doi.org/10.1016/j.neuropsychologia.2012.11.017 
Makous JC, Middlebrooks JC (1990) Two-dimensional sound localization by human listeners. J Acoust Soc Am 87:2188-2200. http://dx.doi.org/10.1121/1.399186

Mann DL, Abernethy B, Farrow D (2010) Action specificity increases anticipatory performance and the expert advantage in natural interceptive tasks. Acta Psychol 135:17-23. http://dx.doi.org/10.1016/j.actpsy.2010.04.006

Mann DT, Williams AM, Ward P, Janelle CM (2007) Perceptual-cognitive expertise in sport: A meta-analysis. J Sport Exerc Psychol 29:457-478. http://dx.doi.org/10.1123/jsep.29.4.457

Middlebrooks JC, Green DM (1991) Sound localization by human listeners. Annu Rev Psychol 42:135-159. http://dx.doi.org/10.1146/annurev.ps.42.020191.001031

Moore BC (2013) An Introduction to the Psychology of Hearing, 6th edn. Brill, Boston, pp 245-246

Mori S, Ohtani Y, Imanaka K (2002) Reaction times and anticipatory skills of karate athletes. Hum Mov Sci 21:213-230. http://dx.doi.org/10.1016/S0167-9457(02)00103-3

Perrett S, Noble, W (1997) The contribution of head motion cues to localization of low-pass noise. Percept Psychophys 59:1018-1026. http://dx.doi.org/10.3758/BF03205517

Röder B, Teder-Sälejärvi W, Sterr A, Rösler F, Hillyard SA, Neville HJ (1999) Improved auditory spatial tuning in blind humans. Nature 400:162-166. http://dx.doi.org/10.1038/22106

Teng S, Puri A, Whitney D (2012) Ultrafine spatial acuity of blind expert human echolocators. Exp Brain Res 216:483-488. http://dx.doi.org/10.1007/s00221-011-2951-1

Van der Stoep N, Van der Stigchel S, Nijboer TCW, Van der Smagt MJ (2016) Audiovisual integration in near and far space: effects of changes in distance and stimulus effectiveness. Exp Brain Res 234:1175-1188. http://dx.doi.org/10.1007/s00221-015-4248-2

Velten MC, Bläsing B, Portes L, Hermann T, Schack T (2014) Cognitive representation of auditory space in blind football experts. Psychol Sport Exerc 15:441-445. http://dx.doi.org/10.1016/j.psychsport.2014.04.010

Velten MC, Ugrinowitsch H, Portes LL, Hermann T, Bläsing B (2016) Auditory spatial concepts in blind football experts. Psychol Sport Exerc 22:218-228. http://dx.doi.org/10.1016/j.psychsport.2015.08.010 
Voss P, Lassonde M, Gougoux F, Fortin M, Guillemot JP, Lepore F (2004) Early-and late-onset blind individuals show supra-normal auditory abilities in far-space. Curr Biol 14:1734-1738. http://dx.doi.org/10.1016/j.cub.2004.09.051

Voss P, Gougoux F, Zatorre RJ, Lassonde M, Lepore F (2008) Differential occipital responses in early-and late-blind individuals during a sound-source discrimination task. Neuroimage 40:746-758. http://doi.org/10.1016/j.neuroimage.2007.12.020

Wan C Y, Wood AG, Reutens DC, Wilson SJ (2010) Early but not late-blindness leads to enhanced auditory perception. Neuropsychologia 48:344-348. http://doi.org/10.1016/j.neuropsychologia.2009.08.016

Ward P, Williams AM (2003) Perceptual and cognitive skill development in soccer: The multidimensional nature of expert performance. J Sport Exerc Psychol 25:93-111. http://dx.doi.org/10.1123/jsep.25.1.93

Wightman F L, Kistler DJ (1999) Resolution of front-back ambiguity in spatial hearing by listener and source movement. J Acoust Soc Am 105:2841-2853. http://dx.doi.org/10.1121/1.426899

Yildirim S, Yuksel R, Doganay S, Gul M, Bingol F, Dane S (2013) The Benefits of Regular Physical Activity on Hearing in Visually Impaired Adolescents. Eur J Basic Med Sci 3:17-21. 


\section{Figure captions}

Fig. 1 Experimental set-up. Four loudspeakers were located in front-left (FL), front-right (FR), back-left $(\mathrm{BL})$, and back-right $(\mathrm{BR})$ positions at a radius of $1.68 \mathrm{~m}$ from the center of a sensor mat. The absolute angle between the axis of each loudspeaker and the frontal plane of the participant was $45^{\circ}$.

Fig. 2 Mean auditory RTs of the three groups on the simple, two-choice, and four-choice RT tasks. The circles represent mean RTs of each individual in the sighted footballers and the nonathletes. The open squares represent mean RTs of each individual in the B1 players. The filled squares represent mean RTs of each individual in the B2 players. The bar represents standard deviation. $* p<.05, * * p<.01, * * * p<.001$ (Bonferroni post-hoc test).

Fig. 3 Mean differences between the choice RTs and simple RTs for the blind and sighted footballers. The open squares represent the mean differences between the choice RTs and simple RTs of each individual in the B1 players. The filled squares represent the mean differences between the choice RTs and simple RTs of each individual in the B2 players. The bar represents standard deviation. ${ }^{*} p<.05, * * p<.01$ (Student's t-test).

Fig. 4 Mean differences between the choice RTs and simple RTs for the longer and shorter groups. The open squares represent the mean differences between the choice RTs and simple RTs of each individual in the B1 players. The filled squares represent the mean differences between the choice RTs and simple RTs of each individual in the B2 players. The bar represents standard deviation. $\dagger p<.1, * p<.05$ (Student's t-test).

Fig. 5 Median correct response rates of the three groups on the two- and four-choice RT tasks. The circles represent median correct response rates of each individual in the sighted footballers and the nonathletes. The open squares represent median correct response rates of each individuals in the B1 players. The filled squares represent median correct response rates of each individual in the B2 players. The upper and the lower edges of each box represent the $75^{\text {th }}$ and $25^{\text {th }}$ percentile, respectively. $* * p<.01$ (Bonferroni 
post-hoc test). 
Table 1. Characteristics of blind football players

\begin{tabular}{cccc}
\hline Participants & Age & Class & Age at onset of visual impairment \\
\hline BF1 & 20 & B2 & Congenital \\
\hline BF2 & 22 & B2 & Congenital \\
\hline BF3 & 25 & B2 & 4 \\
\hline BF4 & 31 & B1 & Congenital \\
\hline BF5 & 29 & B2 & Congenital \\
\hline BF6 & 26 & B2 & 10 \\
\hline BF7 & 33 & B1 & 1.5 \\
\hline BF8 & 25 & B1 & 28 \\
\hline BF9 & 38 & B1 & 23 \\
\hline BF10 & 27 & B1 & \\
\hline
\end{tabular}


Fig. 1

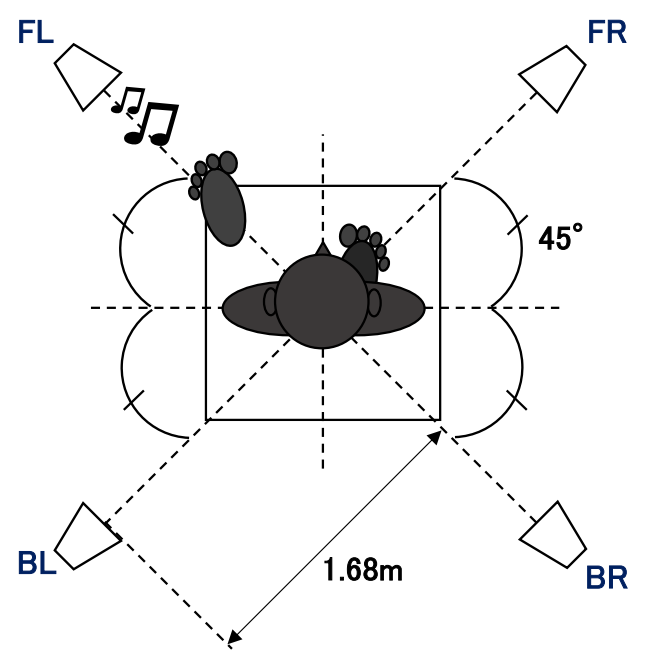


Fig. 2

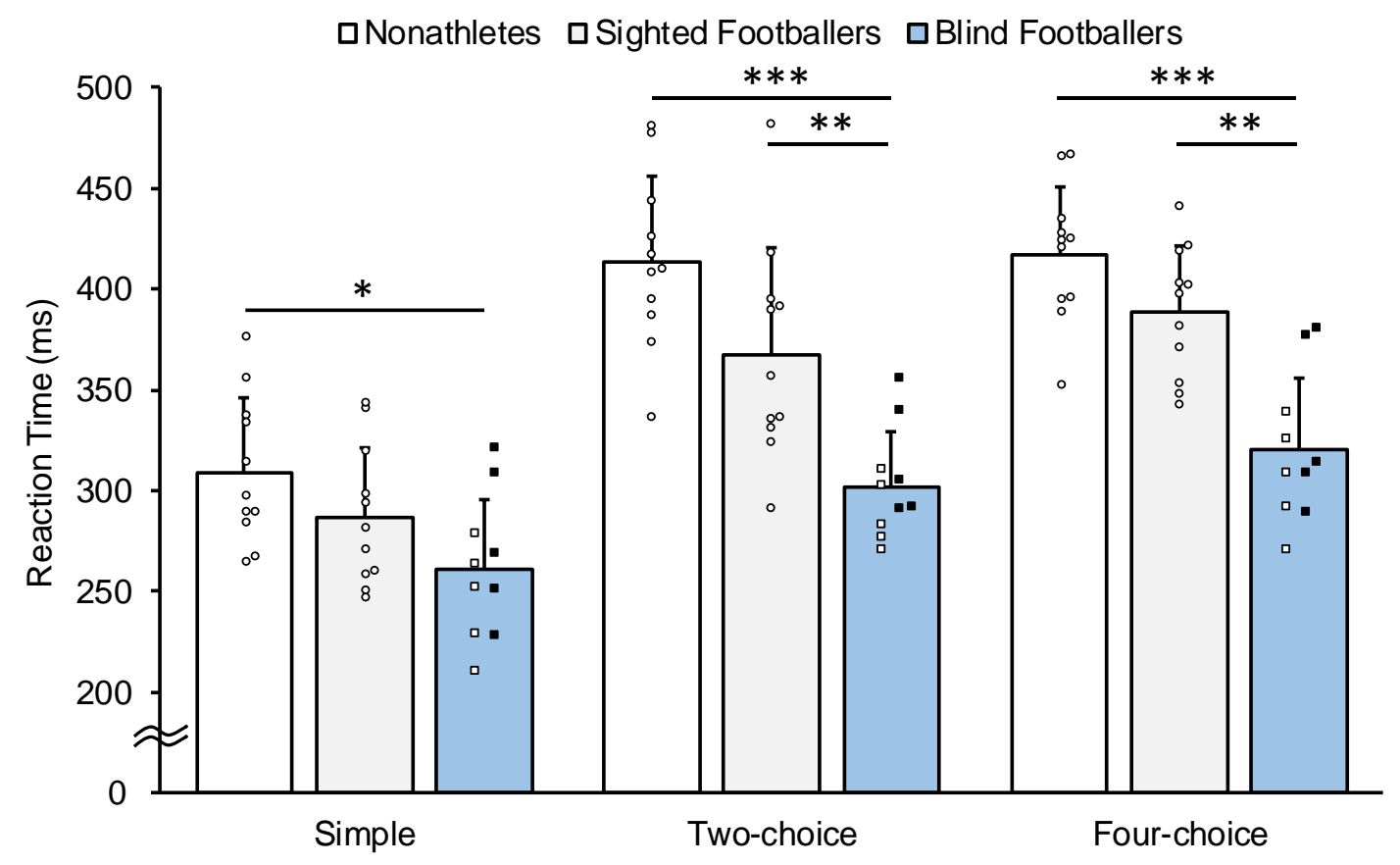


Fig. 3

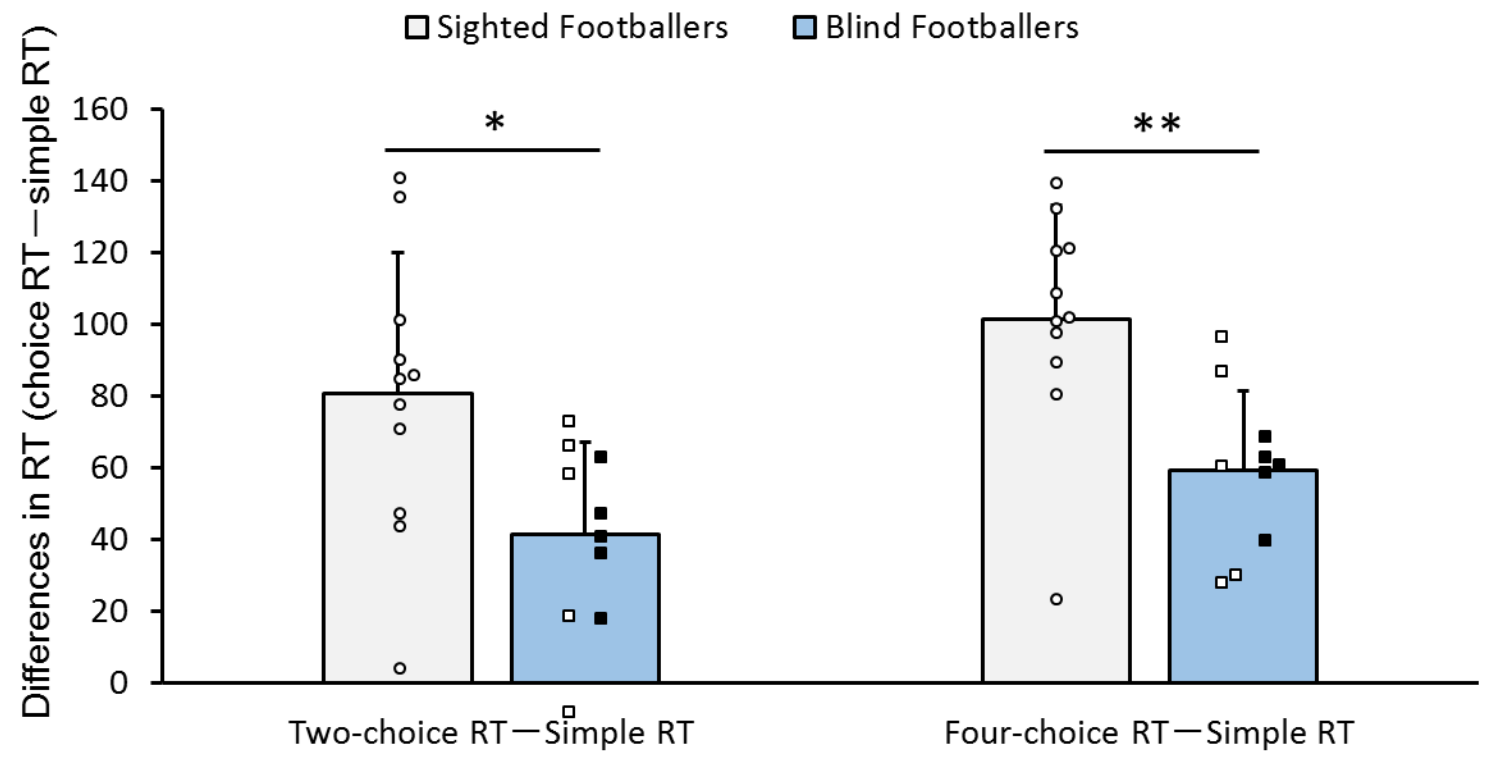


Fig. 4

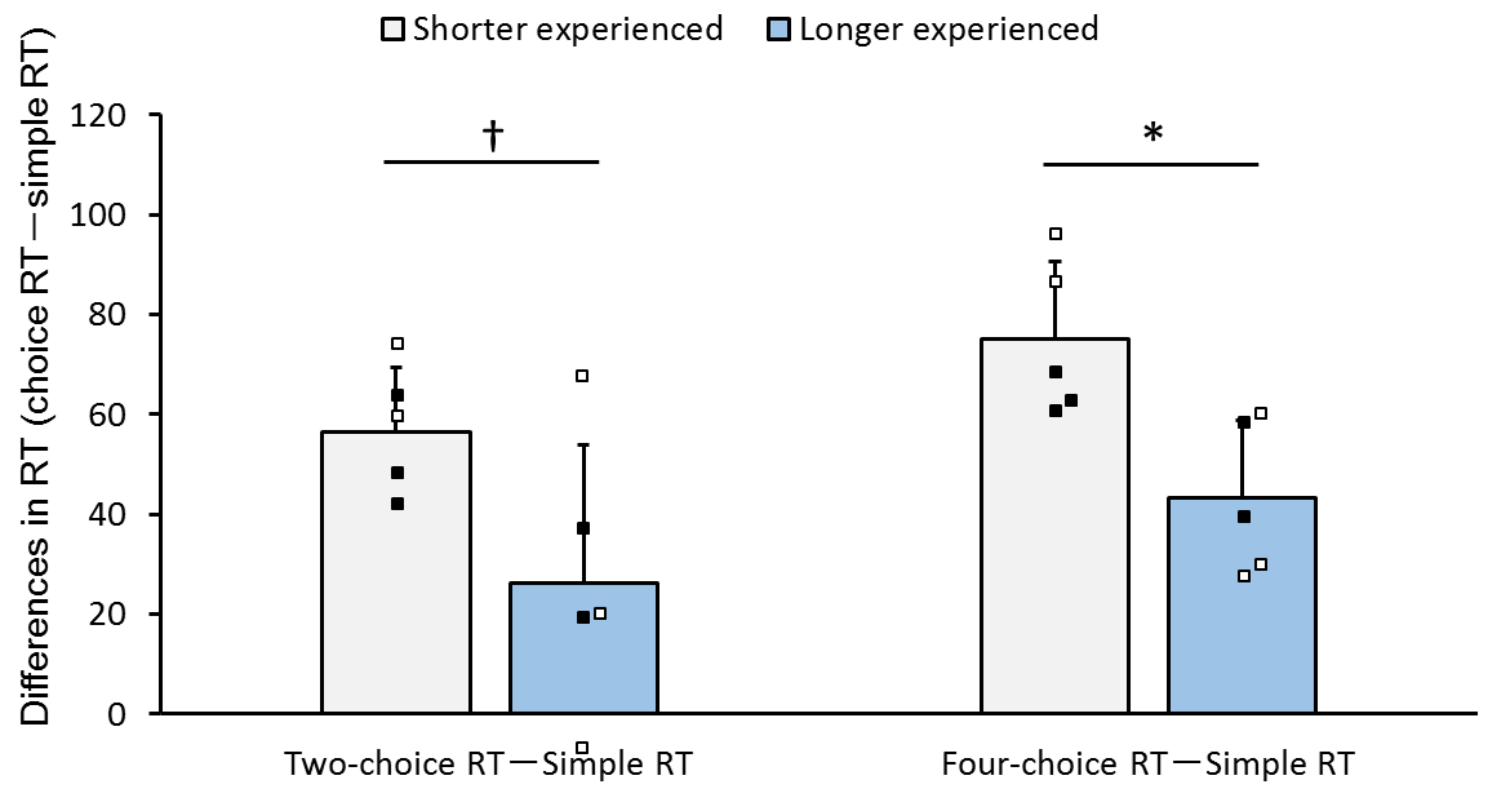


Fig. 5

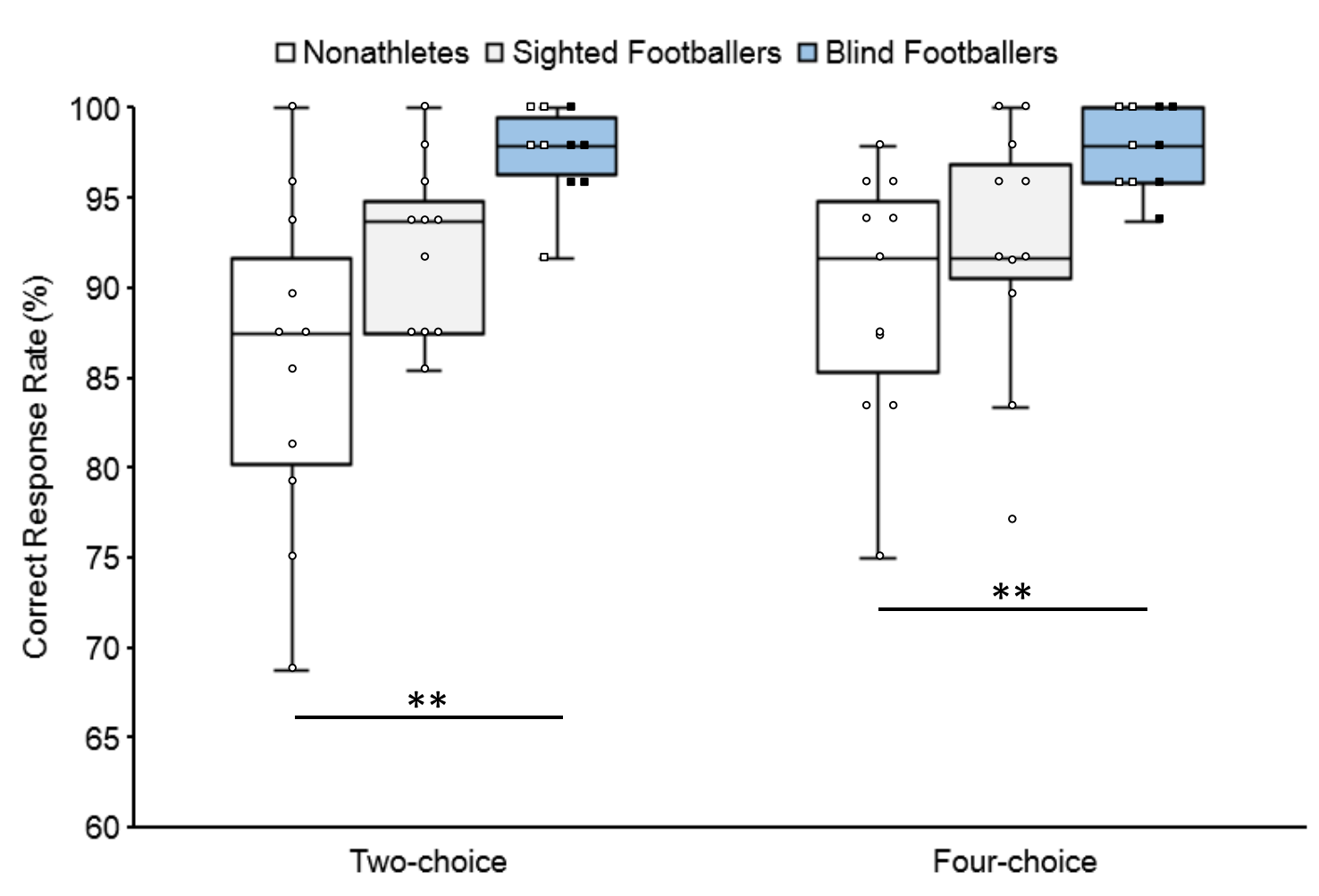

